\title{
PENGARUH WORK DEMAND DAN WORK FLEXIBILITY TERHADAP KINERJA KARYAWAN PT. MANDIRI TUNAS FINANCE DENGAN ORGANIZATIONAL COMMITMENT SEBAGAI VARIABEL INTERVENING
}

\author{
Rina Maretasari ${ }^{\mathrm{a}}$ \\ Dwi Ratmawati $^{\text {b }}$ \\ ${ }^{a}$ Sekolah Pascasarjana Universitas Airlangga ${ }^{b}$ Fakultas Ekonomi dan Bisnis Universitas Airlangga \\ Email: m.rina@inbox.lva ${ }^{a}$ dwi.ratmawati@feb.unair.ac.id ${ }^{b}$
}

ARTICLE HISTORY

Received:

20 Februari 2020

Revised

17 March 2020

Accepted:

1 April 2020

Online available:

9 Mei 2020

Keywords:

work demand, work

flexibility,

organizational

commitment,

employee

performance,

kinerja karyawan

\begin{abstract}
Introduction: Leasing in Indonesia has taken part in corporate financing. Financing companies are also able to grow quite impressively so that they require a lot of manpower, especially in the sales (marketing) and also collection (collector) departments. This study aims to see how Job Demand and Job Flexibility are able to influence Organizational Commitment and ultimately affect employee performance in the marketing and collection departments.

Methods: The sample used in this study were marketing and collection staff at PT. Mandiri Tunas Finance regional area 7 (covering branches Surabaya 1, Surabaya 2, Gresik, Mojokerto, Tuban, Madiun, Kediri, and Malang). The research used quantitative research methods with external and internal model calculations that included validity, reliability, and data analysis using Smart PLS2.0. The analysis technique used for all hypotheses is Partial Least Square.

Results: Testing of marketing and collection staff at PT. Mandiri Tunas Finance in regional 7 produces: (1) Job Demand has a significant effect on Organizational Commitment. (2) Work Flexibility has a significant effect on Organizational Commitment. (3) Organizational Commitment has a significant effect on employee performance and mediates the relationship between Job Demand and Job Flexibility on employee performance.

Conclusion and suggestion: The company is expected to be able to encourage employees to fulfill their job demands without reducing the performance of these employees.
\end{abstract}




\begin{abstract}
ABSTRAK
Hingga saat ini leasing di Indonesia telah ikut berkiprah dalam pembiayaan perusahaan. Perusahaan pembiayaan juga mampu berkembang cukup mengesankan sehingga membutuhkan banyak tenaga kerja terutama di bagian penjualan (marketing) dan juga penagihan (collector). Penelitian ini bertujuan untuk mengetahui bagaimana Work Demand dan Work Flexibility mampu mempengaruhi Organizational Commitment hingga pada akhirnya dapat mempengaruhi kinerja karyawan di bagian marketing dan collection. Sampel yang digunakan dalam penelitian ini adalah staf marketing dan collection pada PT. Mandiri Tunas Finance area regional 7 (meliputi cabang Surabaya 1, Surabaya 2, Gresik, Mojokerto, Tuban, Madiun, Kediri, dan Malang). Penelitian ini menggunakan metode penelitian kuantitatif dengan perhitungan outer dan inner model yang mencakup uji validitas, reabilitas, serta analisis data dilakukan dengan Smart PLS2.0. Teknik analisisyang digunakan untuk semua hipotesis adalah Partial Least Square. Pengujian terhadap staf marketing dan collection pada PT. Mandiri Tunas Finance area regional 7 menghasilkan: (1)Work Demand berpengaruh signifikan terhadap Organizational Commitment. (2)Work Flexibility berpengaruh signifikan terhadap Organizational Commitment. (3)Organizational Commitment berpengaruh secara signifikan terhadap kinerja karyawan dan memediasi hubungan antara Work Demand dan Work Flexibility terhadap kinerja karyawan.
\end{abstract}

\title{
INTRODUCTION
}

Keberhasilan suatu organisasi dalam mencapai tujuannya tergantung pada faktor sumber daya manusia, dimana dibutuhkan suatu interaksi dan koordinasi yang didesain untuk menghubungkan tugas-tugas, baik perseorangan maupun kelompok dalam rangka mencapai tujuan organisasi. Sumber daya manusia merupakan faktor kunci untuk meningkatkan kinerja suatu organisasi. Untuk mewujudkan tujuan yang diinginkan tersebut, maka salah satu cara yang harus ditempuh adalah dengan meningkatkan kinerja karyawan dalam organisasi tersebut. Kinerja merupakan hasil kerja secara kualitas dan kuantitas yang dicapai oleh karyawan dalam melaksanakan tugasnya sesuai dengan tanggung jawab yang diberikan kepadanya.

Setiap perusahaan ingin karyawannya menghasilkan nilai kinerja yang tinggi. Hal semacam ini merupakan keinginan yang ideal bagi perusahaan yang berorientasi pada keuntungan semata, Jimoh (2008) menyatakan bahwa kinerja karyawan merupakan tindakan, perilaku dan hasil yang dapat diukur di mana karyawan terikat, atau yang dilakukan karyawan yang berhubungan dengan tujuan organisasi, dan berkontribusi pada tujuan organisasi, dan untuk mengukur kinerja karyawan diperlukan pengamat

Published by University of Airlangga.

This is an open access article under the CC BY license (https://creativecommons.org/licenses/by-sa/4.0/) 
yang membuat keputusan penilaian terhadap kecenderungan perilaku orang yang dievaluasi, yang berhubungan dengan kontribusi pada tujuan organisasi.

Kinerja individu merupakan tuntutan utama bagi perusahaan agar kelangsungan hidup atau operasional dapat terjamin. Behaviour merupakan bagian budaya yang berkaitan dengan kinerja, hal ini tentunya logis sekali sebab dengan berperilaku karyawan akan dapat memperoleh apa yang dikehendaki dan apa yang diharapkan. Berbagai upaya telah dilakukan manajemen agar terjadi peningkatan kinerja pada setiap karyawanya, salah satunya dengan jalan memperkuat komitmen karyawan terhadap organsasi. Organisasi memberikan kesempatan untuk mengembangkan diri, sedangkan karyawan memberikan dukungan pada organisasi tidak hanya dalam keahlian dan kemampuan saja, tetapi komitmen pada organisasi. Memari et al., (2013) melakukan penelitian terhadap hubungan antara organizational commitment dan kinerja karyawan dimana hasil penelitian menunjukkan hubungan positif antara organizational commitment dan kinerja karyawan.

Grant.R.M (1991) menyatakan bahwa komitmen merupakan elemen penting dalam menentukan hubungan antara sumberdaya dengan kapabilitas organisasi, khususnya kapabiltas untuk mencapai kerja sama dan koordinasi di dalam team kerja yang ada. Hal tersebut mengharuskan perusahaan untuk memotivasi dan meyakinkan sumber daya manusianya agar berorientasi pada rutinitas organisasi.

Pengertian komitmen ini, memang tak lagi sekedar berbentuk kesediaan karyawan menetap di perusahaan dalam jangka waktu lama. Namun lebih penting dari itu, mereka mau memberikan yang terbaik kepada perusahaan, seperti yang terjadi di ruang lingkup pekerjaan sebagai marketing maupun collection, karena tuntutan dan komitmen akan sebuah target menjadi suatu hal yang biasa jika sampai harus melampaui batas yang di wajibkan oleh perusahaan, contoh dalam hal ini adalah jam kerja yang panjang. Dapat dikatakan karyawan hanya dijadikan semacam robot. Kondisi semacam ini akan sulit menumbuhkan komitmen karyawan. Oleh karenanya sangat dibutuhkan pemahaman dari pihak manajemen perusahaan terkait dengan tugas-tugas yang dibebankan kepada karyawannya terkait dengan tuntutan kerja (Work demand). Hart and Staveland (dalam Wikipedia, 2008) mendefinisikan beban kerja sebagai berikut "Sejumlah kegiatan yang membutuhkan proses mental atau kemampuan yang harus diselesaikan dalam jangka waktu tertentu, baik dalam bentuk fisik maupun psikis". Tuntutan pekerjaan selain dapat menyebabkan kelelahan secara fisik bagi karyawan, juga secara psikologis atau disebut sebagai psychological stressor. Tekanan untuk menghadapi kekeliruan atau tuntutan untuk menyelesaiakan tugas dalam waktu yang terbatas dan beban kerja yang berlebihan. Tidak hanya pemahaman mengenai Work demand saja yang dibutuhkan oleh perusahaan guna meningkatkan komitmen karyawan terhadap organisasi tempat ia bekerja, namun juga dibutuhkan adanya fleksibilitas 
terkait dengan pekerjaan yang dilakukan tersebut yang selanjutnya akan disebut dengan work flexibility.

Work flexibility dapat diwujudkan dengan jam kerja per hari yang lebih sedikit atau bekerja pada jumlah jam yang sama tetapi dengan fleksibilitas yang lebih besar. Work flexibility membawa perubahan di lingkungan kerja, dimana karyawan tidak perlu lama bekerja dalam jam yang sama dan atau sebanyak jam yang ditetapkan kantor (Hooks dan Higgs 2000). Dalam penelitian yang dilakukan Lu et al., (2008) menyatakan bahwa work demand memiliki hubungan positif dengan konflik kerja dan keluarga. Begitupula dengan work demand dan family demand yang berhubungan positif dengan konflik keluarga dan pekerjaan. Selanjutnya, konflik kerja dan keluarga berhubungan negatif dengan kepuasan kerja dan organizational commitment. Jadi dapat disimpulkan bahwa work demand dan work flexibility dapat mempengaruhi organizational commitment.

Memandang pembahasan di atas, maka dalam penelitian ini dipilihlah marketing (staf penjualan) dan collection (staf penagihan) di PT. Mandiri Tunas Finance Cabang Surabaya 1, Surabaya 2, Gresik, Mojokerto, Tuban, Madiun, Kediri, dan Malang yang berada di Regional 7 (Jawa Timur, Bali dan Lombok) sebagai objek penelitian, PT. Mandiri Tunas Finance berada di bawah naungan PT Bank Mandiri (Persero) Tbk yang resmi mengakuisisi 51\% (lima puluh satu persen) saham PT Tunas Financindo Sarana. Saat ini PT Mandiri Tunas Finance memberikan solusi pembiayaan yang mudah, inovatif dan kompetitif bagi konsumen untuk memiliki mobil (baru dan bekas), sepeda motor (khusus daerah tertentu), dan kendaraan niaga baik untuk perorangan maupun korporasi. Sampai saat ini, PT Mandiri Tunas Finance memiliki jaringan cabang di 68 titik lokasi yang tersebar di pulau Sumatera, Jawa, Kalimantan, Sulawesi, Bali dan Nusa Tenggara Barat.

Mengingat banyaknya cabang yang nantinya akan bertambah lagi dan semakin berkembang, maka semakin bertambah pula jumlah karyawannya. Pada tahun 2011, jumlah karyawannya mencapai 1.972 orang yang terdiri dari 1.597 karyawan laki-laki dan 375 karyawan wanita. Dan dari data terbaru yang diperoleh, jumlah total keseluruhan karyawan pada tahun 2014 meningkat menjadi 3.056 yang terdiri dari 2.308 karyawan laki-laki dan 748 karyawan wanita. Dengan semakin meningkatnya jumlah karyawan tersebut dan semakin bertambahnya jumlah target penjualan yang harus di capai oleh PT. Mandiri Tunas Finance, maka semakin besar pula kebutuhan marketing (staf penjualan) dan collection (staf penagihan), dan semakin besar pula perhatian yang harus diberikan terhadap karyawannya terkait dengan Work demand dan Work flexibility. Hal tersebut diharapkan mampu meningkatkan komitmen organisasional yang pada akhirnya mempengaruhi kinerja karyawan PT. Mandiri Tunas Finance. 


\section{LITERATURE REVIEW}

\section{Work Demand}

Beberapa ahli menyatakan beberapa pendapatnya mengenai work demand, pendapat itu di antaranya:

1. Work demand adalah aspek fisik, sosial, organisasi, atau psikologis pekerjaan yang memerlukan usaha fisik dan / atau psikologis (kognitif dan emosional) berkelanjutan atau rutin yang berkaitan dengan beban fisiologis dan / atau psikologis tertentu (Bakker \& Demouriti , 2007; Schaufeli \& Bakker, 2004).

2. Meskipun tuntutan pekerjaan tidak selalu merugikan (Van den Broeck, De Cuyper, De Witte, \& Vansteenkiste, 2010), sebagian besar studi memprediksi bahwa kehadiran kondisi kerja yang berlebihan menuntut kapasitas pribadi yang berlebih dari karyawan (Bakker \& Demerouti, 2007) dan memiliki konsekuensi negatif.

3. Karyawan cenderung untuk mempertimbangkan tuntutan pekerjaan sebagai sumber stres dan tuntutan ini memerlukan beban yang tinggi dari usaha mereka (Meijman \& Mulder, 1998).

4. Tuntutan pekerjaan telah ditemukan dapat menantang fisik dan kesejahteraan mental karyawan, yang menyebabkan penurunan energi dan masalah kesehatan (Bakker \& Demerouti, 2007; Bakker, Demerouti, \& Schaufeli, 2003).

5. Menurut Meijman and Mulder (1998) tuntutan pekerjaan berasal dari persyaratan pekerjaan fisik (Misalnya, beban kerja yang berlebihan dan kendala waktu) dan aspek psikologis (misalnya, repetitiveness) dari pekerjaan.

6. Ryan and Deci (2001) menyatakan bahwa kontrol pengalaman psikologis atas tuntutan pekerjaan dapat membantu mengurangi stres dan berhubungan dengan perasaan kesejahteraan dan kepuasan.

7. Menurut Slavitt dalam Iskandar (2001) "Tuntutan tugas atau tuntutan kerja adalah tugas yang harus dilakukan sesuai dengan pekerjaan dan kemampuan yang merupakan tanggung jawab dan kewajibannya atau segala macam tugas atau kegiatan yang harus diselesaikan sebagai bagian reguler dari pekerjaan".

\section{Work Flexibility}

Menurut penelitian yang dilakukan Families and Work Institutes 2002 dalam publikasinya di National Study of The Changing Workforce (NSCW) mengemukakan bahwa elemen utama keefektifan pada tempat kerja adalah Flexibility, ada dua elemen kunci dari fleksibilitas yakni fleksibilitas tempat dan fleksibilitas waktu.

Fleksibilitas kerja merupakan salah satu bentuk upaya perusahaan untuk memproteksi karyawannya. Baiknya perusahaan mampu memberikan fleksibilitas pada karyawannya sehingga mereka tetap tinggal dan tidak berniat untuk keluar dari pekerjaan, Flexibility adalah suatu cara yang digunakan untuk menjelaskan bagaimana dan kapan pekerjaan itu diselesaikan dan bagaimana diorganisasikan. Fleksibilitas kerja 
menawarkan kemudahan bagi karyawan untuk mengkombinasikan, atau mengatur antara aspek pekerjaan dan aspek lain dalam kehidupan. Penelitian menunjukkan bahwa Flexibility juga dapat meningkatkan kepuasan kerja karyawan dan mengurangi stres atau tekanan dalam pekerjaan.

Menurut Lu et al. (2008) menawarkan fleksibilitas pada pekerjaan bisa dengan cara memberikan pekerja otonomi serta kebebasan dalam menentukan kapan dan dimana untuk memulai serta menyelesaikan pekerjaan. Ilgen dan Hollenbeck (1991) dalam Porter dan Ayman (2010) mendefinisikan otonomi sebagai sejauh mana pekerjaan menyediakan substansial kebebasan, kemerdekaan, dan kebijaksanaan pada individu dalam penjadwalan kerja, dan menentukan prosedur yang digunakan untuk melaksanakan pekerjaan. Dengan memberikan fleksibilitas pada pekerjaan, hal tersebut juga merupakan salah satu bentuk dari dukungan dan perhatian manajemen yang diberikan kepada karyawan.

Program mengenai fleksibilitas kerja sangat diperlukan bagi perusahaan. Salah satu cara yang dapat dilakukan perusahaan dalam upaya memberikan fleksibilitas pada perusahaan seperti yang dilakukan oleh Decarufel dan Schan (1990) dalam Porter dan Ayman (2010) menunjukkan bahwa pelaksanaan dari Alternative Work Schedule dapat mengurangi tingkat absensi dan lembur.

\section{Organizational Commitment}

Beberapa pengertian dari komitmen organisasional (Organizational Commitment) seperti yang paling sering digunakan adalah berdasarkan pendapat dari Luthans (1998:148) yaitu :

1.Keinginan yang kuat untuk tetap menjadi anggota organisasi tertentu.

2.Kesediaan untuk berusaha meningkatkan kemampuan diri atas nama organisasi.

3.Keyakinan yang pasti dan penerimaan nilai-nilai dan tujuan dari organisasi.

Dengan kata lain, komitmen organisasional adalah loyalitas karyawan pada organisasinya, dan proses yang berlanjut di mana anggota organisasi menunjukkan perhatian mereka terhadap keberhasilan organisasi.

Sementara itu Newstrom dan Davis (1993:198) mendefinisikan komitmen organisasional sebagai derajat, di mana karyawan dapat diidentikan dengan organisasi dan berkeinginan untuk terus berpartisipasi secara aktif dalam organisasi tersebut. Dengan demikian komitmen organisasional merupakan ukuran kemauan karyawan untuk tinggal atau bertahan dalam perusahaan sampai nanti. Komitmen organisasional juga mencerminkan kepercayaan karyawan pada misi dan tujuan organisasi, kemauan untuk 
melakukan usaha-usaha tertentu dalam mencapai misi dan tujuan itu, serta berniat untuk terus bekerja pada organisasi tersebut.

Robbins (2001:140) berpendapat bahwa "komitmen pada organisasi merupakan suatu keadaan dimana seorang karyawan memihak pada suatu organisasi tertentu dan tujuan-tujuannya serta berniat memelihara keanggotaan dalam organisasi itu".

Pendapat yang serupa juga dikemukakan oleh Greenberg dan Baron (1993:174) yang memberikan definisi bahwa :

"Komitmen pada organisasi sebagai alat yang merefleksikan derajat seorang individu diidentikkan dan terlibat dengan organisasi serta tidak berkeinginan untuk meninggalkan organisasi tersebut. Identifikasi pada organisasi diartikan sebagai kondisi saling membagi tujuan dari anggota-anggota organisasi, merasa memiliki organisasi adanya loyalitas pada organisasi. Sedangkan keterlibatan pada organisasi dipandang sebagai keinginan individu untuk terlibat secara aktif guna mencapai tujuan organisasi dan senantiasa mendukung tujuan tersebut".

\section{Kinerja Karyawan}

Kinerja adalah sebuah kata dalam bahasa Indonesia dari kata dasar "kerja" yang menterjemahkan kata dari bahasa asing prestasi. Bisa pula berarti hasil kerja. Kinerja menurut Mangkunegara (dalam Nugroho, 2007) "Kinerja ( prestasi kerja ) adalah hasil kerja secara kualitas dan kuantitas yang dicapai oleh seseorang pegawai dalam melaksanakan tugasnya sesuai dengan tanggung jawab yang diberikan kepadanya".

Menurut Rivai (2004) mengemukakan kinerja adalah : "Merupakan perilaku yang nyata yang ditampilkan setiap orang sebagai prestasi kerja yang dihasilkan oleh karyawan sesuai dengan perannya dalam perusahaan".

Sehingga dapat disimpulkan kinerja adalah prestasi dan hasil kerja yang yang dicapai seseorang dalam melaksanakan tugas-tugas yang dibebankan kepadanya yang didasarkan atas kecakapan, pengalaman dan kesungguhan serta waktu dihasilkan oleh karyawan sesuai dengan perannya dalam perusahaan.

\section{Hipotesis}

H1: Work Demand memiliki pengaruh yang signifikan terhadap Organizational Commitment

H2: Work Flexibility memiliki pengaruh yang signifikan terhadap Organizational Commitment

H3: Organizational Commitment memiliki pengaruh yang signifikan terhadap kinerja karyawan.

H4: Work Demand memiliki pengaruh langsung terhadap kinerja karyawan

H5: Work Flexibility memiliki pengaruh langsung terhadap kinerja karyawan. 
H6: Organizational Commitment memiliki pengaruh yang signifikan terhadap kinerja karyawan dan memediasi hubungan antara Work Demand dan Work Flexibility terhadap kinerja karyawan.

\section{RESEARCH METHODS}

Jenis penelitian ini merupakan penelitian diskriptitf kuantitatif. Pengujian hipotesis penelitian dilakukan dengan pendekatan Structural Equation Model (SEM) berbasis Partial Least Square (PLS). Dalam penelitian ini populasi yang akan digunakan adalah seluruh staff marketing dan collection pada area regional 7 (meliputi cabang Surabaya 1, Surabaya 2, Gresik, Mojokerto, Tuban, Madiun, Kediri, dan Malang) yang diantaranya tidak diwajibkan menyelesaikan pekerjaan di dalam kantor. Dan jam bekerja mereka juga dipandang fleksibel asalkan dapat memenuhi target yang sudah ditetapkan oleh perusahaan. Di dalam PT. Mandiri Tunas Finance sendiri terdapat 867 orang karyawan pada divisi collection dan 1.104 orang pada divisi marketing yang tersebar di seluruh cabang di Indonesia. Sedangkan pada area regional 7 (meliputi cabang Surabaya 1, Surabaya 2, Gresik, Mojokerto, Tuban, Madiun, Kediri, dan Malang) total staf di bagian marketing dan collection adalah 91 orang dengan rincian sebagai berikut:

Tabel 1

Data Staf Marketing dan Collection area regional 7 (Jawa Timur) PT. Mandiri Tunas Finance

\begin{tabular}{lcc}
\hline \multicolumn{1}{c}{ Cabang } & Jumlah Staf Marketing & Jumlah Staf Collection \\
\hline Surabaya 1 & 9 & 5 \\
Surabaya 2 & 18 & 4 \\
Gresik & 4 & 1 \\
Mojokerto & 4 & 1 \\
Tuban & 4 & 4 \\
Madiun & 6 & 4 \\
Kediri & 7 & 7 \\
Malang & 8 & 5 \\
\multicolumn{1}{c}{ Total = 91 orang } & 60 & 31 \\
\hline
\end{tabular}


RESULT AND ANALYSIS

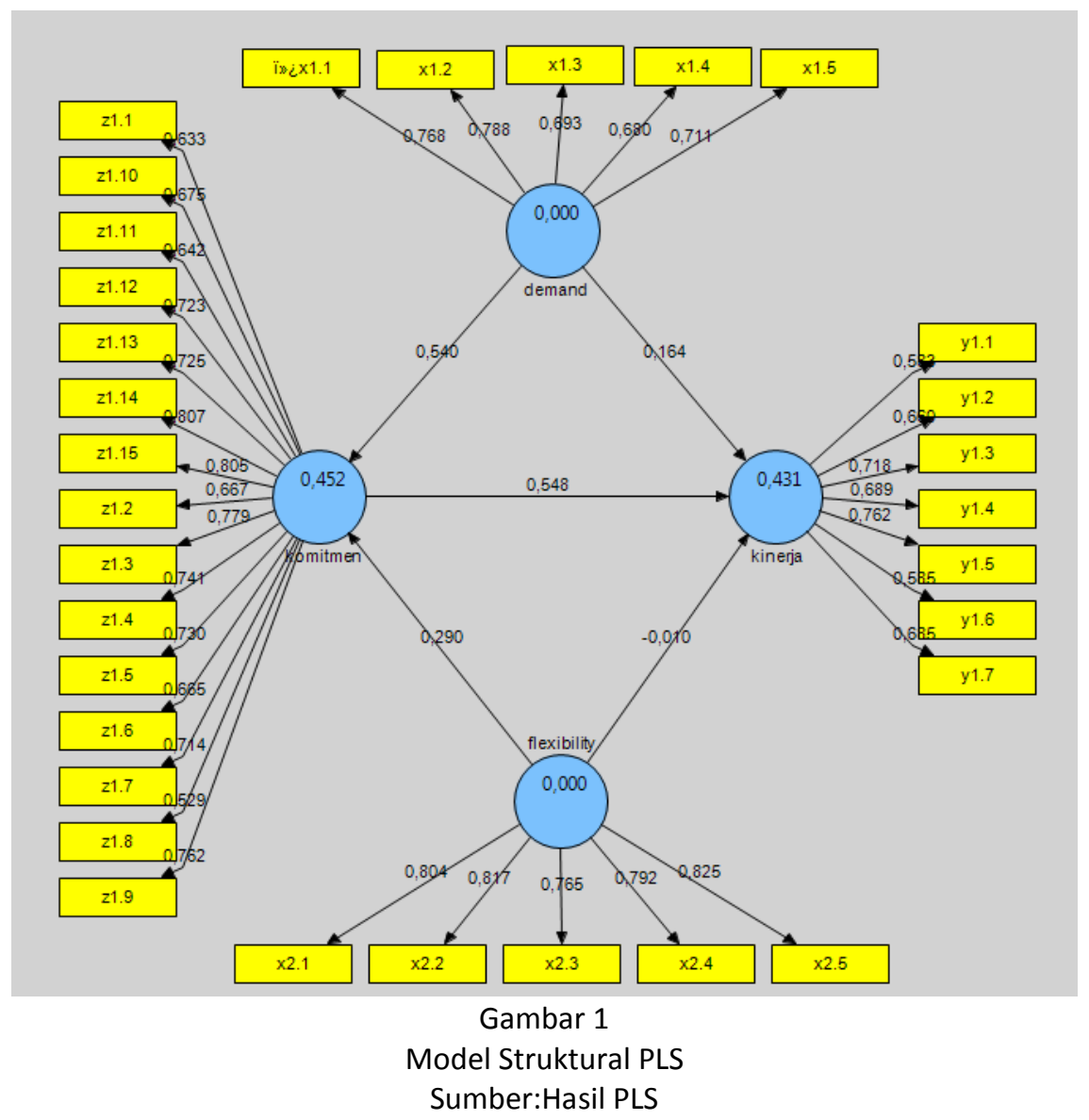

Work demand berpengaruh secara signifikan terhadap organizational commitment

Hasil menunjukkan terdapat pengaruh positif dan signifikan antara work demand terhadap organizational commitment dengan nilai koefisien path pengaruh work demand terhadap organizational commitment adalah 0.540 dengan t hitung 9.344 yang lebih besar dari t tabel. Jadi semakin tinggi work demand semakin tinggi organizational commitment dari PT Mandiri Tunas Finance Area Regional 7. Begitu pula sebaliknya, semakin semakin rendah work demand semakin rendah organizational commitment dari PT Mandiri Tunas Finance Area Regional 7

Dalam menyelesaikan pekerjaanya yang selalu terkait dengan target yang ditentukan, tentu saja para marketing dan collector memerlukan usaha fisik dan psikologis (kognitif dan emosional) berkelanjutan atau rutin yang berkaitan dengan beban fisiologis dan psikologis tertentu (Bakker \& Demouriti , 2007; Schaufeli \& Bakker, 2004). Dan dengan beban kerja yang tinggi dalam pengujian ini, ternyata para marketing dan collector memiliki commitment organizational yang tinggi, hal ini dapat pula dibuktikan dengan jumlah karyawan yang bekerja antara 3-4 tahun yaitu sejumlah 37 
orang dan ada 5 orang yang bekerja lebih dari atau sama dengan 5 tahun pada PT. Mandiri Tunas Finance.

Pengaruh work demand terhadap organizational commitment yang significant ini ditunjukkan dengan penilaian responden bahwa tuntutan kerja yang diberlakukan pada karyawan PT Mandiri Tunas Finance Area Regional 7 cukup tinggi, hal tersebut dibuktikan dengan nilai mean tertinggi sebesar 3.41 pada indikator yang menyatakan bahwa tuntutan untuk selalu peduli terhadap kebutuhan para customer terkait dengan layanan yang diberikan perusahaan cukup tinggi. Dan juga komitmen karyawan pada PT Mandiri Tunas Finance dinilai responden tinggi, hal tersebut dibuktikan dengan nilai mean tertinggi sebesar 4.23 dengan kategori sangat tinggi pada indikator yang menyatakan bahwa karyawan bangga bercerita kepada orang lain bahwa dia merupakan bagian dari organisasi.

\section{Work flexibility berpengaruh secara signifikan terhadap organizational commitment}

Hasil pengujian statistik menunjukkan terdapat pengaruh positif dan signifikan antara work flexibility terhadap organizational commitment dengan nilai koefisien path pengaruh work flexibility terhadap organizational commitment adalah 0.290 dengan $\mathrm{t}$ hitung 4.713 yang lebih besar dari t table. Berarti semakin tinggi work flexibility semakin tinggi organizational commitment dari PT Mandiri Tunas Finance. Sebaliknya semakin rendah work flexibility semakin rendah organizational commitment dari PT Mandiri Tunas Finance Area Regional 7.

Dari hasil pengujian diatas, nampak jika tingginya nilai work flexibility yang merupakan aspek yang terkait dengan kemampuan dari para marketing dan collector dalam mempengaruhi atau membuat keputusan mengenai bagaimana, apa, dan kapan pekerjaan dilakukan atau diselesaikan (Langfred dan Moye, 2004 dalam Porter dan Ayman, 2010) mampu mempengaruhi organizational commitment. Di mana dalam perusahaan sendiri telah menentukan targetnya bagi para marketing dan collector namun tidaklah memberikan jam kerja yang kaku bagi mereka dalam menyelesaikan target setiap bulanya. Jam kerja yang diberikan berbeda dengan karyawan di bagian administrasi yang harus berada di dalam kantor setiap hari senin sampai dengan jum'at pukul 08.30 hingga pukul 16.30 dan di hari sabtu mulai pukul 08.30 sampai dengan 14.30. Dalam penelitian ini, terbukti bahwa work flexibility mampu meningkatkan organizational commitment.

Pengaruh work flexibility terhadap organizational commitment yang significant ini ditunjukkan dengan penilaian respinden bahwa flexibilitas kerja yang diberikan pada karyawan PT Mandiri Tunas Finance Area Regional 7 adalah tinggi, hal tersebut dibuktikan dengan nilai mean tertinggi sebesar 3.87 pada indikator x2.5 dengan kategori

tinggi yang menyatakan bahwa perusahaan selalu memberikan flexibilitas dalam 
penetuan hari kerja karyawan. Dan juga dengan penilaian responden terkait dengan komitmen karyawan pada PT Mandiri Tunas Finance yang dinilai tinggi oleh responden, hal tersebut dibuktikan dengan nilai mean tertinggi sebesar 4.23 pada indikator z1.6 dengan kategori sangat tinggi yang menyatakan bahwa karyawan bangga bercerita kepada orang lain bahwa dia merupakan bagian dari organisasi.

Organizational commitment berpengaruh secara signifikan terhadap kinerja karyawan

Hasil pengujian statistik menunjukkan terdapat pengaruh positif dan signifikan antara organizational commitment terhadap kinerja karyawan dengan nilai koefisien path pengaruh organizational commitment terhadap kinerja karyawan adalah 0.431 dengan t hitung 6.654 yang lebih besar dari t table. Hal ini berarti bahwa semakin tinggi organizational commitment semakin bagus kinerja karyawan dari PT Mandiri Tunas Finance Area Regional 7. Dan sebaliknya, semakin rendah organizational commitment semakin buruk kinerja karyawan dari PT Mandiri Tunas Finance Area Regional 7.

Berdasarkan dari hasil pengujian statistik di atas, menunjukkan nilai yang tinggi dari organizational commitment yang merupakan suatu keadaan dimana seorang karyawan memihak pada suatu organisasi tertentu dan tujuan-tujuannya, serta berniat memelihara keanggotaan dalam organisasi itu (Robbins, 2001:140). Tingginya nilai statistik dari organizational commitment ini mempengaruhi kinerja karyawan yang merupakan catatan tentang hasil-hasil yang diperoleh dari fungsi-fungsi pekerjaan tertentu atau kegiatan dalam kurun waktu yang telah ditentukan. Hal ini tentu saja menjelaskan bahwa komitmen organisasi yang tinggi dari para para marketing dan collector mampu mendorong mereka untuk dapat memperoleh hasil kinerja yang bagus dalam memenuhi setiap target yang telah ditentukan oleh perusahaan baik target penjualan bagi para marketing maupun target penagiahan bagi para collector.

\section{Work Demand memiliki pengaruh langsung terhadap kinerja karyawan}

Hasil pengujian statistik menunjukkan terdapat pengaruh positif dan tidak signifikan antara work demand terhadap kinerja karyawan dengan nilai koefisien path pengaruh work demand terhadap kinerja karyawan adalah 0.164 dengan t hitung 1.561 yang lebih kecil dari t table. Hal ini berarti bahwa semakin tinggi work demand semakin bagus kinerja karyawan dari PT Mandiri Tunas Finance Area Regional 7. Dan sebaliknya, semakin rendah work demand semakin buruk kinerja karyawan dari PT Mandiri Tunas Finance Area Regional 7.

\section{Work Flexibility memiliki pengaruh langsung terhadap kinerja karyawan}

Hasil pengujian statistik menunjukkan terdapat pengaruh negatif dan tidak signifikan antara work flexibility terhadap kinerja karyawan dengan nilai koefisien path pengaruh work flexibility terhadap kinerja karyawan adalah -0.010 dengan t hitung 0.093 yang lebih kecil dari t table. Hal ini berarti bahwa semakin tinggi work flexibility semakin buruk kinerja karyawan dari PT Mandiri Tunas Finance Area Regional 7. Dan sebaliknya, 
semakin rendah work flexibility semakin bagus kinerja karyawan dari PT Mandiri Tunas Finance Area Regional 7.

Organizational commitment berpengaruh secara signifikan terhadap kinerja karyawan dan memediasi hubungan antara Work Flexibility terhadap kinerja karyawan

Pengaruh dari organizational commitment terhadap kinerja karyawan yang significant dapat ditunjukkan pada hasil keseluruhan responden menilai bahwa komitmen karyawan pada PT Mandiri Tunas Finance dinilai responden tinggi dan dikung dengan kinerja karyawan pada PT Mandiri Tunas Finance Area Regional 7 dinilai responden tinggi, hal tersebut dibuktikan dengan nilai mean tertinggi sebesar 4.05 pada indikator y1.4 dengan kategori tinggi yang menyatakan tingginya ide karyawan dalam penyelesaian persoalan yang terjadi dalam pekerjaan.

Hasil pengujian statistik menunjukkan terdapat pengaruh positif dan signifikan antara organizational commitment terhadap kinerja karyawan dengan nilai koefisien path pengaruh organizational commitment terhadap kinerja karyawan adalah 0.431 dengan t hitung 6.654 yang lebih besar dari t table. Hal ini berarti bahwa semakin tinggi organizational commitment semakin bagus kinerja karyawan dari PT Mandiri Tunas Finance Area Regional 7. Dan sebaliknya, semakin rendah organizational commitment semakin buruk kinerja karyawan dari PT Mandiri Tunas Finance Area Regional 7. Dengan adanya pembuktian bahwa work demand dan work flexibility yang menunjukkan bahwa tidak terdapat pengaruh yang signifikan terhadap kinerja karyawan pada keduanya, sehingga disimpulkan bahwa organizational commitment memediasi secara penuh (full mediation) pengaruh work demand dan work flexibility terhadap kinerja karyawan.

\section{CONCLUSION}

Berdasarkan pada penelitian yang telah dilakukan, maka dapat ditarik beberapa kesimpulan. Hipotesis pertama penelitian yang menduga adanya pengaruh signifikan antara work demand terhadap organizational commitment menunjukkan terdapat pengaruh positif dan signifikan. Hipotesis kedua menunjukkan terdapat pengaruh positif dan signifikan antara work flexibility terhadap organizational commitment, jadi semakin tinggi work flexibility semakin tinggi organizational commitment dari PT Mandiri Tunas Finance Area Regional 7. Hipotesis ketiga penelitian menunjukkan terdapat pengaruh positif dan signifikan antara organizational commitment terhadap kinerja karyawan. Hipotesis keempat penelitian yang menduga adanya pengaruh signifikan antara work demand terhadap kinerja karyawan tidak dapat diterima. Hal ini menunjukkan terdapat pengaruh positif dan tidak signifikan antara work demand terhadap kinerja karyawan. Hipotesis kelima penelitian yang menduga adanya pengaruh signifikan antara work

Published by University of Airlangga.

This is an open access article under the CC BY license (https://creativecommons.org/licenses/by-sa/4.0/) 
flexibility terhadap kinerja karyawan tidak dapat diterima. Hal ini menunjukkan terdapat pengaruh negatif dan tidak signifikan antara work flexibility terhadap kinerja karyawan. Hipotesis keenam penelitian yang menduga Organizational Commitment memiliki pengaruh yang signifikan terhadap kinerja karyawan dan memediasi hubungan antara Work Demand dan Work Flexibility terhadap kinerja karyawan dapat diterima dan terbukti kebenarannya.

Berdasarkan hasil penelitian yang telah dilakukan maka saran yang dapat diberikan pada PT. Mandiri Tunas Finance khususnya Area Regional 7 adalah sebagai berikut:

1. Dari hasil penelitian mengenai Work Demand yang diperoleh, di mana pada PT Mandiri Tunas Finance Area Regional 7 memiliki rata-rata Work Demand yang cukup tinggi. Dengan demikian, saran yang dapat diberikan bagi perusahaan adalah mengimbangi tuntutan kerja yang cukup tinggi ini dengan berbagai imbalan atau reward yang dapat membuat karyawan mampu bertahan di perusahaan lebih lama dan juga tidak mengalami stres dalam menjalankan pekerjaanya

2. Hasil penelitian mengenai Work Flexibility yang diperoleh, di mana pada PT Mandiri Tunas Finance Area Regional 7 memiliki rata-rata Work flexibility yang tinggi. Mengingat nilai Work Flexibility yang lebih tinggi dari Work Demand, maka sebaiknya PT. Mandiri Tunas Finance tetap mempertahankan fleksibilitas terhadap aturan terkait penyelesaian pekerjaan bagi karyawan di bagian marketing dan para collector.

3. Dengan adanya Work Demand yang cukup tinggi dan diimbangi dengan Work Flexibility yang tinggi, hasil dari penelitian ini menunjukkan Organizational Commitment yang tinggi. Saran bagi PT. Mandiri Tunas Finance khususnya karyawan marketing dan para collector adalah tetap mempertahankan komitmen terhadap organisasinya dengan tujuan mencapai kinerja yang tinggi bagi setiap karyawannya.

4. Penelitian ini juga menunjukkan nilai rata-rata yang tinggi untuk kinerja karyawan marketing serta collector PT. Mandiri Tunas Finance. Adapun saran bagi perusahaan adalah semakin meningkatkan kinerja karyawan yang ada di dalamnya agar perusahaan mampu memenuhi target yang diberikan perusahaan yang meliputi target penjualan bagi marketing maupun juga penagihan bagi collector, baik target setiap bulanya maupun target tahunan.

5. Perusahaan diharapkan mampu mendorong karyawan untuk bisa memenuhi job demandnya tanpa menurunkan kinerja dari karaywan tersebut.

\section{REFERENCES}

Anies. 2010. Akibat Tuntutan Kerja Yang Terlalu Tinggi, (online), (http://www.suararnerdeka.com, diakses 18 Mei 2014).

Bakker, A. B., Demerouti, E., de Boer, E., \& Schaufeli, W. B. (2003). Job demands and job resources as predictors of absence duration and frequency. Journal of Vocational Behavior, 62(2), 341-356. 
Baron, R.A. and Greenberg, J. 1993. Behavior in organizations: Understanding and managing side of work. Prentice Hall International, Inc. New Jersey. .2000. Behavior in organizations: Understanding and managing side of work. Prentice Hall International, Inc. New Jersey.

Bernardin, H. John and Joyce, E.A. Russel. 1993. Human Resource Management An Experiential Approach. New York: McGraw-Hill. Series In Management.

Cappuccio, Francesco. 2011. Kebiasaan Yang Memperburuk Kesehatan, (online), (http ://w ww.obatpropolis.com, diakses 29 Mei 2014).

Davis, Keith and W.Newstrom. 1999. Perilaku Dalam Organisasi. Edisi ketujuh. Jakarta: Erlangga.

. 1993. Human Resource at Work: Organizational Behavior. Eight, Singapore: Mc. Graw -Hill International Edition.

Dharma.1991. Manajemen Prestasi Kerja .Rajawali Pers

Fletcher, C. 2001. Hospital RNs' job satisfactions and dissatisfactions. Journal of Nursing Administration, 31 (6), 324-331.

Ghozali, I. (2006), Aplikasi Analisis MultivariatProgram SPSS, cetakan IV, Semarang: Badan Penelitian Universitas Diponegoro, Hal. 82.

Gomez, Faustino Cardoso. 2002. Manajemen Sumber Daya Manusia . Edisi Kedua. Penerbit Andi Offset, Yogyakarta

Grant, R. M,. 1991. "Prospering in dynamically-competitive environments: Organizational capability as knowledge integration". Organization Science, 7(4), 375-387.

Hart and Staveland, 2008 Theory and modeling(Online) (http://en.wikipedia.org/wiki/Workload, diakses 5 Januari 2014)

Jimoh, A.M., 2008, "Emotional Labour, Conscientiousness and Job Tenure as Predictors of Job Performance Among University Administrative Workers in Southwestern Nigerian", International Journal of African \& African American Studies, Vol.VII, No.2

Karsono. 2008. Pengaruh Komitmen Organisasi Terhadap Kinerja dengan Motivasi dan Kepuasan Kerja sebagai Variabel Pemediasi. Jurnal Akuntansi Bisnis. Vol.8(2): 151 -164.Surakarta.

Kattenbach, Ralph et al. 2010. Flexible working times: effects on employees' exhaustion,work-nonwork conflict and job performance. Emerald Group Publishing Limited Vol 15 No. 3 pp:279-295.

Lu, luo et al. 2008. Work/Family Demand, Work Flexibility, Work/Family Conflict, and Their Consequences at Work: A National Probability Sample in Taiwan. International Journal of Stress Management, Vol.15. No.I. pp:I-21.

Luthans, Fred. 1998. Organizational Behaviour. Prentice Hall Inc., Englewood Cliff., New Jersey.

Malo, Manasse \& Sri Trisnoningtias. 2000. Metode Penelitian Masyarakat. Jakarta : Pusat antar Universitas IImu-ilmu Sosial, Universitas Indonesia.

Margiati. 1999. Pengertian Dan Pengenalan Stres, (online), (http://multvplylogo.com, diakses 20 Mei 2014). 
Meijman, T. F., \& Mulder, G. 1998. Psychological aspects of workload in P.J.D. Drenth,H. Thierry, \& C.. de Wolff (Eds.), Handbook of work and organisational psychology (2nd ed., pp. 5-33). Hove, England: Psychology Press/Erlbaum.

Memari, Negin. Maideh,Omid. Marnani, Ahmad Barati. 2013. The impact of Organizational Commitment on Employees Job Performance. "A study of Meli bank". Interdisciplinary Journal of Contemporery Research in Bussines vol 5, no 5.pp: 164-171

Meyer, J.P. and Allen, N.J. 1998. Commitment in the Workplace Theory, Research and Application. Sage Publications. New Delhi.

Mowday, Potter. 1999. Implication Of Organizational Commitment. New Jersey: Prentice Hall International Editions.

Nawawi, Hadari et.al. 2006. Kepemimpinan yang Efektif. Yogyakarta : UGM Press

Nollen, S.D. 1981. The compressed workweek: is it worth the effort? Industrial Engineer, Vol. 13, pp. 58-64.

Porter S ,Ayman R .2010 .Work Flexibility as a Mediator of the Relationship between Work Family Conflict and Intention to Quit , Journal of Management and Organization, 16(3) 411-424.

Putra, Yanuar Surya \& Hari Mulyadi. 2010. Pengaruh Faktor Job Demand Terhadap Kinerja Karyawan dengan Burnout sebagai Variabel Moderating pada Karyawan Bagian Produksi PT. Tripilar Betonmas Salatiga. Among Makarti, Vol.3 No.6

Riduwan \& Engkos Achmad Kuncoro. 2008. Cara Menggunakan dan Memakai Analisis Jalur (Path Analysis). Bandung: penerbit Alfa Beta.

Rivai, Veithzal. 2004. Kepemimpinan dan Perilaku Organisasi. Jakarta : PT RajaGrafindo Persada

Robbins, S.P.. 1998. Organization Behavior, Concepts, Controvercies, Application, seventh edition, Englewood Cliffs 2001. Organizational behaviour. New Jersey: Prentice-Hall, Inc . 2006. Perilaku Dalam Organisasi., Terjemahan. Jakarta: PT. Indeks Kelompok

GramediaRonen, S. and Primps, S.B. 1981. The compressed workweek as organizational change: behaviours and attitudinal outcomes. Academy of Management Review, Vol. 6 No. 1,pp. 61-74.

Ryan ,R.M., \& Deci,E.L. 2001. To be happy or to be self - fulfilled: A review of research on hedonic and eudaimonic well- being. In S. Fiske (Ed.), Annual Review of Psychology (Vol. 52; 141 - 166). Palo Alto, CA: Annual Reviews/ Inc.

Santoso, Singgih. 2003. SPSS Statistik Multivariat. Jakarta : PT Elex Mdia Komputindo. Simamora, Henry. 2001. Manajemen Sumber Daya Manusia. STIE YKPN. Yogyakarta. Solimun. 2005. Structural Equation Modeling (SEM): Aplikasi Software AMOS. Malang: FMIPA Universitas Brawijaya.

Sudarmanto, R. Gunawan. 2005. Analisis Regresi Linear Ganda dengan SPSS. Yogyakarta: Graha Ilmu.

Sugiyono. 2003. Metode Penelitian Bisnis. Cetakan ke-5. Bandung: penerbit Alfa Beta. Umiker. 1999. Pembentukan Komitmen Organisasi Dalam Perusahaan. Jakarta. PT. Gramedia Pustaka Utama. 
Van den Broeck, A., De Cuyper, N., De Witte, H., \& Vansteenkiste, M. (2010). Not all job demands are equal: Differentiating job hindrances and job challenges in the Job Demands-Resources model. European journal of work and organizational psychology, 19(6), 735-759.

Werther, W.B. \& Davis, K. 1996. Human Resources and Personnel Management. $5^{\text {th }}$ Ed.Boston: McGraw-Hill.

Yarnest. 2004. Panduan Aplkasi Statistik. Malang: Dioma. 